\title{
ABRASION WEAR RESISTANCE OF SELECTED HVOF SPRAYED WCCOCr COATINGS
}

\author{
${ }^{1}$ Sofia KŠIŇANOVÁ, ${ }^{2}$ Marek VOSTŘÁK, ${ }^{3}$ Žaneta DLOUHÁ \\ 1,2,3Research and Testing Institute Plzeň, Pilsen, Czech Republic, EU, \\ ksinanova@vzuplzen.cz,votrak@vzuplzen.cz, dlouha@vzuplzen.cz
}

https://doi.org/10.37904/metal.2021.4205

\begin{abstract}
The HVOF (high-velocity oxygen fuel) technology is one of the most used processes for carbide-based coatings application. These coatings are suitable, for example, to replace hard chromium plating. In order to select the right coating for a given application, it is necessary to know the key properties. The aim of this study is to analyze and compare the abrasion wear resistance of HVOF sprayed coatings based on tungsten carbide (WC-CoCr). The structure of the coatings and their resistance to abrasive wear are analyzed and discussed.
\end{abstract}

Keywords: HVOF, thermal spraying, Abrasion resistance, Abrasion wear, WCCoCr coatings

\section{INTRODUCTION}

With thermal spraying technology, it is possible to increase the functional properties of the surface of various components. The wear and corrosion resistance, thermal insulation or biocompatibility can be affected by using the right coating material. High velocity oxy-fuel (HVOF) thermal spraying is often used in industry for components heavily stressed for wear or corrosion. Thanks to their high speed and temperature of up to 5500 $\mathrm{K}$, they are used for spraying metals, metallic alloys and especially cermets and superalloys. Low porosity, compact and dense microstructure, moderate oxidation level and high bonding strength is typical for coatings made by HVOF. Cermets and superalloys are most often sprayed with this technology. [1] The aim of this study is to compare microstructure and abrasion wear resistance of selected HVOF sprayed WC-CoCr coatings. This type of coatings has ceramic tungsten monocarbide phase (WC) and a softer metal binder phase ( $\mathrm{CoCr}$ ). Thanks to this, WC cermet coatings show excellent resistance to abrasive and erosive wear. These coatings could be suitable replacement for hard chromium plating. Properties of the coating are influenced by properties of the used powder (material composition, grain size, size of carbides) and used spray parameters. [2] [3] The aim of this study is to compare commercially used powders of the same chemical composition but with different properties such as particle size, primary carbide particle size or method of production and to determine their resistance to abrasion.

\section{EXPERIMENTAL PROCEDURE}

\subsection{Material characteristics}

Three materials from different companies or with different size of particles were tested. The chemical composition of all materials is shown in Table 1. All other information such as the name of the producer, particle size, primary size of carbide particles and method of production of the powder are showed in (Table 2). 
Table 1 Chemical composition of tested materials [5] [6] [7] [8] [9] [10]

\begin{tabular}{|c|c|c|c|c|c|c|}
\hline & \multicolumn{7}{|c|}{ Weight Percent (nominal) } \\
\hline Material & W & Co & C (total) & Cr & Fe max & Total all other \\
\hline WC-731/1350VF & Bal. & $9.0-11.0$ & $5.0-5.5$ & $3.0-5.0$ & 0.4 & 1.5 \\
\hline WC-731/1350VM & Bal. & $9.5-10.5$ & $5.0-5.5$ & $3.5-4.5$ & 0.4 & 1.5 \\
\hline Amperit 507.074 & Bal. & $9.0-11.0$ & $5.2-6.2$ & $3.5-5.0$ & 0.3 & 0.2 \\
\hline Amperit 508.072 & Bal. & $9.0-11.0$ & $5.3-6.2$ & $3.5-5.0$ & 0.3 & 0.2 \\
\hline Woka 3652 FC & Bal. & $8.5-11.5$ & $3.4-4.6$ & $4.8-5.6$ & 0.2 & \\
\hline Amdry 5843 & Bal. & $9.0-11.0$ & $4.9-6.0$ & $3.1-4.9$ & 1.0 & 1.0 \\
\hline
\end{tabular}

Table 2 Information about tested materials [5] [6] [7] [8] [9] [10]

\begin{tabular}{|c|c|c|c|c|}
\hline Material & Producer & Particle size & $\begin{array}{c}\text { Primary Carbide } \\
\text { Particle Size }\end{array}$ & Method of production \\
\hline WC-731/1350VF & \multirow[t]{2}{*}{ Praxair } & $-38+11 \mu \mathrm{m}$ & Fine & \multirow[t]{5}{*}{ Agglomerated and sintered } \\
\hline WC-731/1350VM & & $-38+11 \mu \mathrm{m}$ & Medium & \\
\hline Amperit 507.074 & \multirow[t]{2}{*}{ Höganäs } & $-45+15 \mu \mathrm{m}$ & Fine & \\
\hline Amperit 508.072 & & $-38+10 \mu \mathrm{m}$ & Medium & \\
\hline Woka 3652 FC & \multirow[t]{2}{*}{ Oerlikon Metco } & $-45+15 \mu \mathrm{m}$ & Fine & \\
\hline Amdry 5843 & & $-45+16 \mu \mathrm{m}$ & Medium & Sintered and crushed \\
\hline
\end{tabular}

\subsection{Spraying parameters}

All materials were sprayed by HVOF thermal spraying technology (used gun: Tafa JP 5220). Spraying parameters are showed in (Table 3). Deposition distance was $380 \mathrm{~mm}$, amount of the powder was $2 \times 80 \mathrm{~g} / \mathrm{min}$ ( $80 \mathrm{~g} / \mathrm{min}$ for each feeder). The parameters were chosen on the basis of previous optimalization, where samples from each material were sprayed with different parameters.

Table 3 Spraying parameters of tested materials

\begin{tabular}{|c|c|c|}
\hline Material & Equivalence ratio & Combustion chamber pressure [bar] \\
\hline WC-731/1350VF & 0.75 & 8.6 \\
\hline WC-731/1350VM & 0.85 & 7.2 \\
\hline Amperit 507.074 & 0.75 & 8.6 \\
\hline Amperit 508.072 & 0.66 & 8.1 \\
\hline Woka 3652 FC & 0.75 & 8.6 \\
\hline Amdry 5843 & 0.75 & 8.6 \\
\hline
\end{tabular}

\subsection{Evaluation methods}

\subsubsection{Abrasion wear resistance}

The abrasive wear is an intensive degradation process. Experimental results of laboratory tests can help with the selection of the best material for parts that are working in conditions of abrasion. To test the abrasive resistance of coatings, a dry sand rubber wheel testing machine according to ASTM G-65 standard was used. This test includes the so-called three-body (sample - abrasive - disc) abrasion. The test conditions are called "Low stress abrasion", which means that the abrasive grains do not break or crush during the test. The planar specimen is pressed with a constant force against a rotating disk with a rubber rim. A constant amount of 
abrasive is poured between the sample and the disc, which causes wear. Three samples from each coating were tested and the results are the average of these three measurements. Parameters of this method are shown in (Table 4). Because tested materials have similar composition, the evaluation factor is the accumulated weight loss. [10] [11]

Table 4 Parameters of abrasion wear resistance test

\begin{tabular}{|c|c|}
\hline Compression force [N] & 22 \\
\hline Abrasive material & White corundum with a grain size of F70 $(212-250 \mu \mathrm{m})$ \\
\hline Total abrasive path [m] & $718 \quad$ (Divided into five identical cycles) \\
\hline
\end{tabular}

\subsubsection{Microstructure}

The microstructure of the coatings was evaluated on the coating cross-section prepared according to the standard method for metallographic sample preparation. The coatings were evaluated on the Arsenal AM 2203-T optical microscope. The evaluation factors are the occurrence of cracks and fissures, the homogeneity of the coating, the shape, size and distribution of the mats, the porosity, the content and distribution of oxide inclusions or other impurities.

\section{RESULTS}

\subsection{Microstructure}

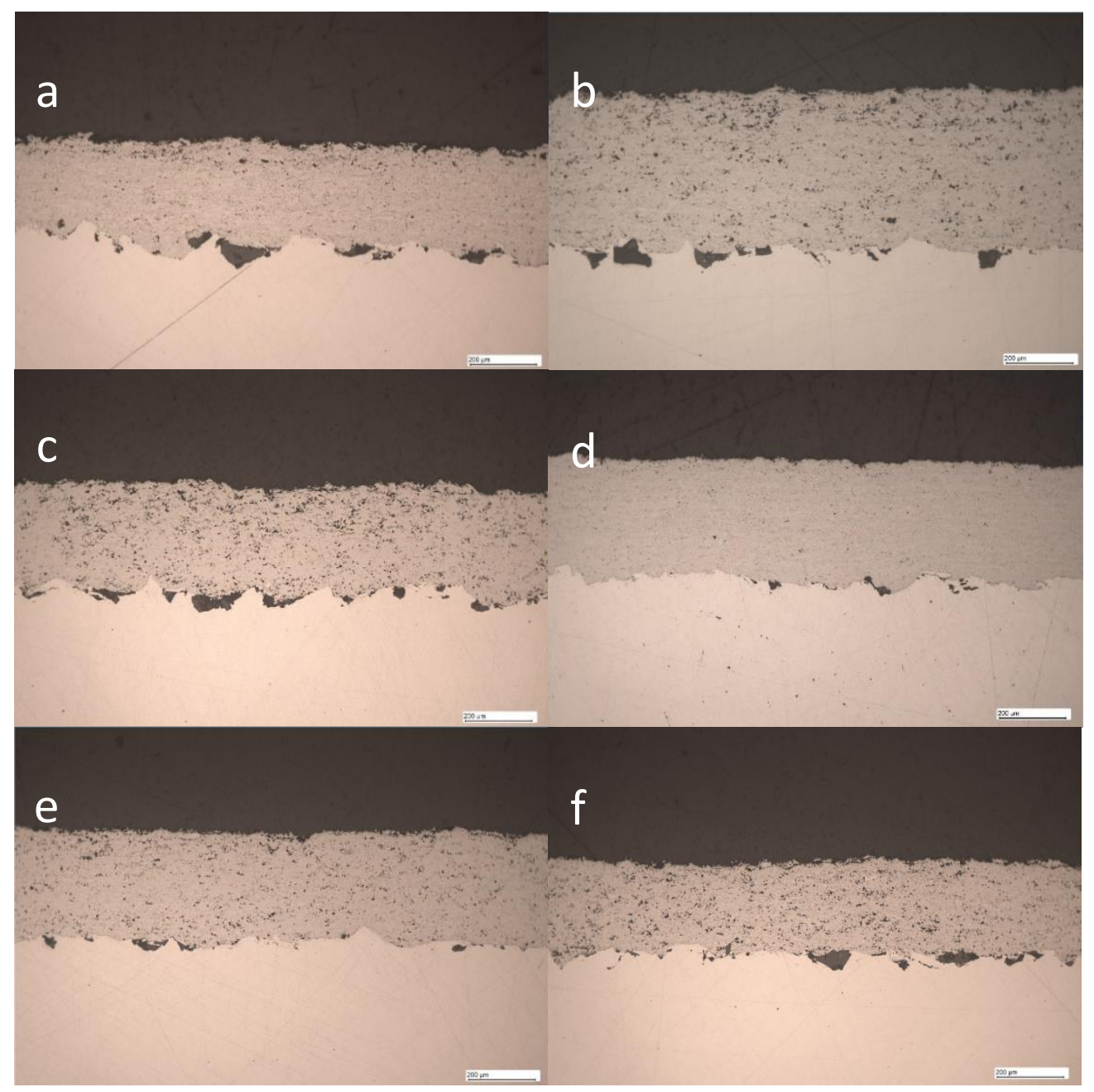

Figure 1

Microstructure of tested materials:

a) WC-731/1350VF, b) WC-731/1350VM, c) Amperit 507.074, d) Amperit 508.072, e) Woka 3652 FC, f) Amdry 5843 
Photos of microstructure are shown in (Figures 1a-1f). For all coatings is microstructure typical for WC-CoCr coatings prepared by HVOF. There are typical pores, patches, corundum stuck at the interface as it is usual for those types of coating. The lower layer is denser, the upper layers are more porous. The grain size of the Amperit 508.072 (Figure 1d) is slightly different from the others, seems more dense and solid.

\subsection{Abrasion wear resistence}

Slope of abrasive line of cumulative mass loss of each tested material is showed in (Figure 2).

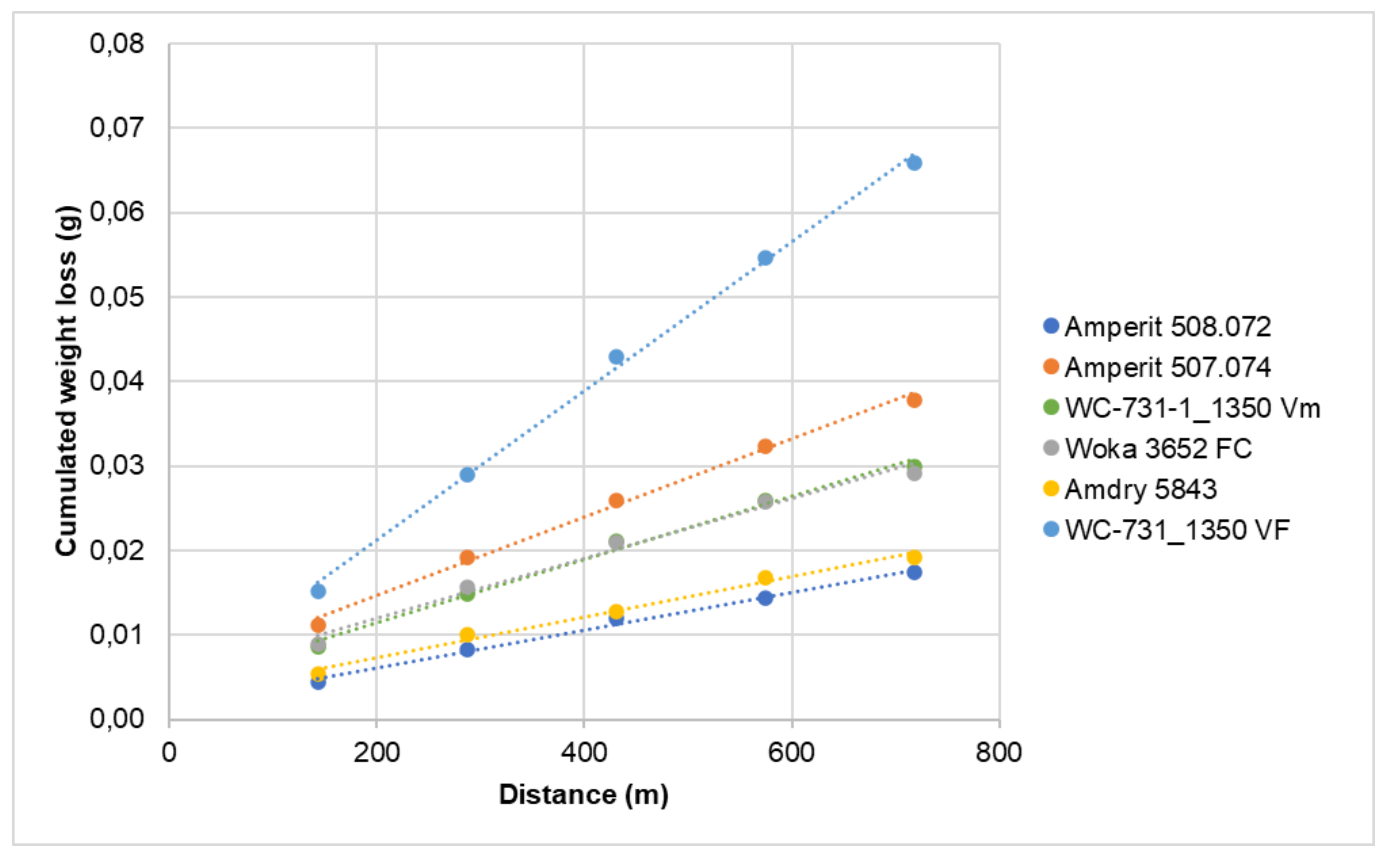

Figure 2 Abrasion wear resistance of tested materials

In Table 5, the powders are sorted according to the results of abrasive testing (from the best results - Amperit 508.072 , to the worst - WC-731 / 1350VF). It can be seen from the table that both size of the parts and primary carbide particle size affects the results of abrasive wear.

Table 5 Material characteristics according to abrasion results sorted from best to worst

\begin{tabular}{|c|c|c|c|c|}
\hline Material & $\begin{array}{c}\text { Abrasive mass } \\
\text { loss line slope }\end{array}$ & Particle size & Method of production & $\begin{array}{c}\text { Primary Carbide } \\
\text { Particle Size }\end{array}$ \\
\hline Amperit 508.072 & $2.23615 \mathrm{E}-05$ & $-38+10 \mu \mathrm{m}$ & Agglomerated and sintered & Medium \\
\hline Amdry 5843 & $2.39554 \mathrm{E}-05$ & $-45+16 \mu \mathrm{m}$ & Sintered and crushed & Medium \\
\hline Woka 3652 FC & $3.53064 \mathrm{E}-05$ & $-45+15 \mu \mathrm{m}$ & & Fine \\
\hline WC-731/1350VM & $3.75348 \mathrm{E}-05$ & $-38+11 \mu \mathrm{m}$ & \multirow{3}{*}{ Agglomerated and sintered } & Medium \\
\cline { 1 - 2 } Amperit 507.074 & $4.63788 \mathrm{E}-05$ & $-45+15 \mu \mathrm{m}$ & & Fine \\
\hline WC-731/1350VF & $8.83008 \mathrm{E}-05$ & $-38+11 \mu \mathrm{m}$ & & Fine \\
\cline { 5 - 5 }
\end{tabular}

\section{CONCLUSION}

A total of 6 WC-CoCr commercial powders, which are commonly used in production, were tested. All coatings were prepared by HVOF technology. Subsequently, the microstructure of the coating was evaluated and the samples were subjected to an abrasion resistance test according to ASTM G-65. 
According to the results of abrasive testing, it can be stated that the size of the parts affects the results of abrasive wear as much as the primary carbide particle size. It could be interesting to investigate the behaviour of coatings when changing the grain size of the used abrasive material.

The WC-731/1350 VF has the worst results (highest slope of the abrasive wear curve). This can be caused by both the properties of the powder or through human fault. Therefore, it is recommended to repeat for further research.

\section{ACKNOWLEDGEMENTS}

The paper has originated in the framework of the solution of project number FW01010017 "Replacement of surface anticorrosive and sliding layers of aerospace materials with more environmentally friendly technologies"co-financed by Technology Agency of the Czech Republic in the operational programme TREND.

\section{REFERENCES}

[1] Handbook of thermal spray technology [online]. Materials Park: ASM International, 2004 [cit. 2021-06-10]. ISBN 0-87170-795-0.

[2] PICAS, Josep A., PUNSET, Miquel, BAILE, M. Teresa, MARTíN, Enric, FORN, Antonio. Properties of WC-CoCr Based Coatings Deposited by Different HVOF Thermal Spray Processes. Plasma Processes and Polymers. 2009, vol. 6 , no. 1, pp. 948-953. ISSN 16128850.

[3] PICAS, J.A., PUNSET, M., RUPÉREZ, E., MENARGUES, S., MARTIN, E., BAILE, M.T. Corrosion mechanism of HVOF thermal sprayed WC-CoCr coatings in acidic chloride media. Surface and Coatings Technology. 2019, vol. 371, pp. 378-388. ISSN 02578972.

[4] SUCHÁNEK, J., BROŽEK M. Abrasive wear resistance of selected hardfacing materials. Czech Technical University, Mechanical Engineering Faculty, Dept. Manufacturing Technology.

[5] OERLIKON METCO. Amdry 5843 10lb: Product Description [online]. [viewed: 2021-05-12]. Available from: https://mymetco.oerlikon.com/en-us/article/1001069.

[6] HÖGANÄS. Amperit 507: Powders for thermal spraying [online]. [viewed: 2021-05-12]. Available from: https://www.hoganas.com/globalassets/download-media/stc/PD-4111.pdf.

[7] HÖGANÄS. Amperit 508: Powders for thermal spraying [online]. [viewed: 2021-05-12]. Available from: https://www.hoganas.com/globalassets/download-media/stc/pd-4127.pdf.

[8] PRAXAIR. WC-731-1/1350VM products: SAFETY DATA SHEET [online]. [viewed:2021-05-12]. Available from: https://www.astroalloys.com/assets/pdfs/praxair/wc-731s-1350vms.pdf.

[9] PRAXAIR. WC-731-1/1350VM products: SAFETY DATA SHEET [online]. [viewed: 2021-05-12]. Available from: https://www.astroalloys.com/assets/pdfs/praxair/wc-731s-1350vms.pdf.

[10] OERLIKON METCO. Woka 3652 FC 5kg: Product Description [online]. [viewed: 2021-05-12]. Available from: https://mymetco.oerlikon.com/en-us/article/1050441. 